\title{
Clinical significance of self-descriptive apathy assessment in patients with neurological form of Wilson's disease
}

\author{
Marcin Leśniak ${ }^{1} \cdot$ Magdalena Roessler-Górecka² $\cdot$ Anna Członkowska ${ }^{2} \cdot J^{2}$ oanna Seniów ${ }^{2}$ (i)
}

Received: 15 February 2021 / Accepted: 29 May 2021 / Published online: 14 June 2021

(c) The Author(s) 2021

\begin{abstract}
Background and aim Apathy is one of the neuropsychiatric symptoms of Wilson's disease (WD) which typically affects the brain's fronto-basal circuits. Lack of agreed diagnostic criteria and common use of self-description assessment tools lead to underestimation of this clinical phenomenon. The aim of this study was to investigate whether subjective and informantbased clinical features of apathy in patients with WD enable clinicians to make a valid diagnosis.

Methods Multiple aspects of goal-oriented behavior were assessed in 30 patients with the neurological form of WD and 30 age-matched healthy participants using two questionnaires, the Lille Apathy Rating Scale (LARS) and the Dysexecutive Questionnaire (DEX). Both included a self-descriptive and a caregiver/proxy version. Cognitive functioning was estimated with the use of Addenbrooke's Cognitive Examination-Revised.

Results Patients obtained significantly worse scores on all clinical scales when more objective measures were considered. Features of apathy and executive dysfunction were revealed in patients' caregiver versions of LARS and DEX, which may indicate poor self-awareness of patients with WD. Roughly $30 \%$ of participants were likely to present with clinically meaningful symptoms, independent of cognitive dysfunction.

Conclusions Methods relying on self-description appear inferior to informant-based scales when diagnosing apathy. More objective criteria and measurement tools are needed to better understand this clinical syndrome.
\end{abstract}

Keywords Wilson's disease $\cdot$ Apathy syndrome $\cdot$ Psychopathology $\cdot$ Cognitive impairment $\cdot$ Self-description

\section{Introduction}

Wilson's disease (WD) is a rare, autosomal recessive, inherited disease in which mutation of the ATP7B gene on chromosome 13 induces an adenosine triphosphate (ATP) synthesis deficiency $[1,2]$. As a consequence, excess copper accumulates in various organs, including the liver, cornea, kidney, brain, and, especially, the basal ganglia. Clinical presentation may involve predominantly hepatic, neurological, or psychiatric symptoms. Neuropsychological profiles of the neurological form of WD are not fully investigated since this population is very heterogenous [3, 4]. Patients with brain involvement, in addition to movement disorders and

Joanna Seniów

seniowj@ipin.edu.pl

1 Faculty of Psychology, University of Warsaw, Warsaw, Poland

2 Institute of Psychiatry and Neurology, Sobieskiego 9, 02-957 Warsaw, Poland other neurological symptoms, frequently show impairment of basic cognitive functions (memory, attention, and visuospatial processing) and executive functions of varying intensity $[5,6]$. These symptoms may be accompanied by mood disorders, personality change, impulsivity, irritability, and other behavioral abnormalities, as well as psychosis [7]. To date and to the best of our knowledge, no research focused on apathy syndrome in WD has been published, although it is commonly reported in pathology-comprising basal ganglia and their neuronal loops with prefrontal cortex $[8,9]$.

Apathy is frequently revealed in neurodegenerative diseases with basal ganglia dysfunction, such as Parkinson's disease (PD) [10], progressive supranuclear palsy [11], Huntington's disease [12], and focal lesions due to vascular or traumatic brain injury, especially if the caudate, internal pallidum, and medial-dorsal thalamic nuclei are damaged $[8,13]$. Apathy is associated with significant problems, including reduced independence in everyday life, poor response to treatment, and caregiver distress [14]. Clinically, however, apathy continues to be under-recognized, partly due to the lack of universal diagnostic criteria and tools [15]. 
Apathy has been defined either as an individual symptom or as a complex syndrome with diminished drive and motivation and/or action initiation as the main feature [16]. As a consequence, prominent reduction of goal-oriented behavior is clinically observed. According to Marin's definition [17], this motivational deficit is not attributable to diminished level of consciousness, cognitive impairment, or emotional distress. Although some symptoms overlap, the apathetic condition can also manifest independently of depressive disorder [17].

According to some authors, apathy syndrome may be fractionated into components or affected domains: emotional, cognitive, and behavioral [16], incorporating conditions such as poor emotional responsiveness, indifference, lack of concern and intellectual curiosity, and reduced voluntary goal-directed behavior [18]. Multidimensional attitude towards the differential diagnosis of apathy has been frequently postulated. Previous authors have indicated the need for diagnostic tools designed for specific clinical symptomatology, allowing description of apathy profiles or even subtypes, independent of physical disability or anosognosia (i.e., by obtaining additional data from informants) $[18,19]$.

Apathy in WD may be a serious clinical problem, worthy of attention during assessment and treatment as well as during psychological work with patients' families. However, due to frequent metacognitive dysfunction and limited selfawareness of this patient population, relying on self-report methods may pose a considerable threat to the validity of such an assessment.

Consequently, the main goal of this study was to investigate whether subjective and informant-based clinical features of apathy in patients with the neurological form of WD are consistent enough to allow clinicians draw practical conclusions.

We have taken the hypothesis of occurrence of apathy in WD patients not only on the basis of our clinical experience, but also relying on literature indicating that it is common when the executive (initiating and control) system for goaldirected behavior is altered [20]. The executive disorders are typical when neuronal prefrontal-basal ganglia loops are dysfunctional, as a feature of WD. Hence, apathy was assessed in the context of executive functioning, especially in regards to its metacognitive and behavioral aspects.

We also aimed to evaluate relationships between apathy and cognitive functioning to determine whether these entities are separable or co-occurring, which could suggest mutual pathomechanisms.

\section{Methods}

\section{Participants}

Thirty patients with chronic, neurological WD admitted to the Department of Neurology were enrolled in the study (Table 1). Inclusion criteria were (1) diagnosis of WD based on clinical symptom assessment, laboratory tests, and genetic analysis [21], (2) age of 18-65 years, and (3) duration of illness no shorter than 4 years (with stable medical condition and adjusted pharmacotherapy). Exclusion criteria were (1) severe somatic state (significantly hindering psychological examination), (2) limited consciousness, (3) overt affective syndromes (i.e., depression, mania), (4) coexisting neurological disorders other than WD, (5) poor compliance (i.e., irregular medication), and (6) severe communication or perception disorders that may interfere with performance on the assessment.

Thirty age-matched healthy individuals were used as a control group. They were recruited from volunteers (persons visiting other patients hospitalized in the Department of Neurology). The inclusion criteria were (1) age $18-65$ years and (2) no history of any neurological or psychiatric condition.

The characteristics of patients and controls are presented in Table 2. Magnetic resonance imaging (MRI) was available for $23(77 \%)$ of the participants. In most cases, results showed increased signals primarily in the basal ganglia, specifically globus pallidus $(n=13 ; 57 \%)$, putamen $(n=7 ; 30 \%)$, and caudate $(n=4 ; 17 \%)$. In a few exams, changes were also observed in the thalamus $(n=3$; $13 \%)$, cerebellum $(n=3,13 \%)$, and/or pons $(n=3 ; 13 \%)$. In some patients, brain atrophy was reported, generalized $(n=5 ; 22 \%)$ or limited to the cerebellum $(n=6 ; 26 \%)$, as well as ventricular enlargement $(n=7 ; 30 \%)$. The patients exhibited various neurological symptoms ranging from mild to moderate, with the most common being dysarthria $(n=24 ; 80 \%)$ and tremor $(n=23 ; 77 \%)$. Less common were gait disturbance $(n=12 ; 40 \%)$ and/or drooling $(n=11 ; 37 \%)$. Next in order of frequency included dysphagia $(n=6 ; 20 \%)$, involuntary movements $(n=6 ; 20 \%)$, psychomotor slowing $(n=3 ; 10 \%)$, imbalance $(n=1 ; 3 \%)$, major change in mimic expression $(n=1 ; 3 \%)$, and rigidity $(n=1 ; 3 \%)$.

\section{Procedure}

One experienced clinical neuropsychologist (M.R-G.) conducted the assessment of all study participants during individual sessions under optimal conditions. Informants were family members (most frequently, spouses) or close caregivers. The interview and questionnaire were conducted individually. An informed consent was obtained in all cases. The study was approved by the local Bioethics Committee. All medical information was derived from the neurological department's WD database. 


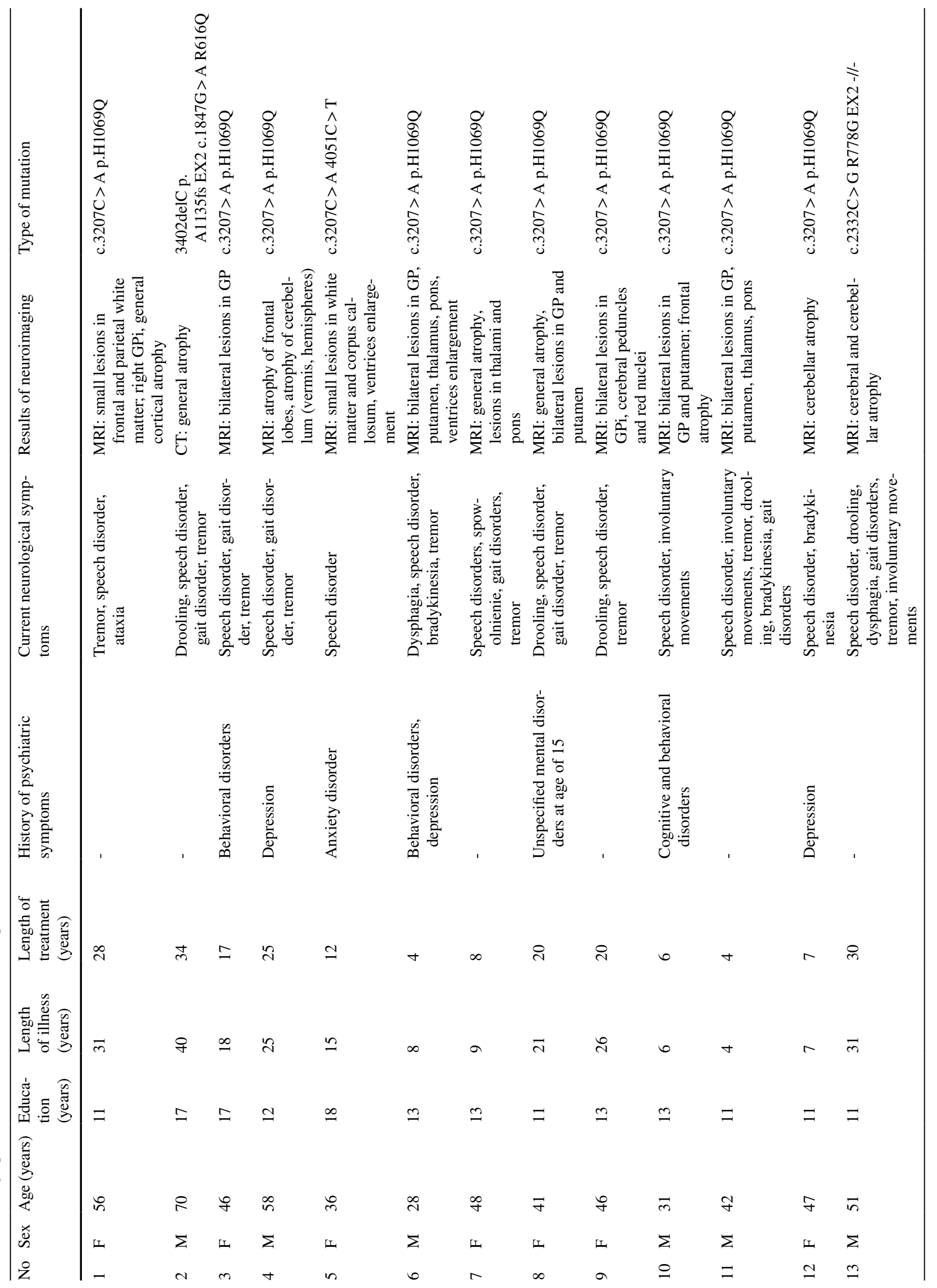




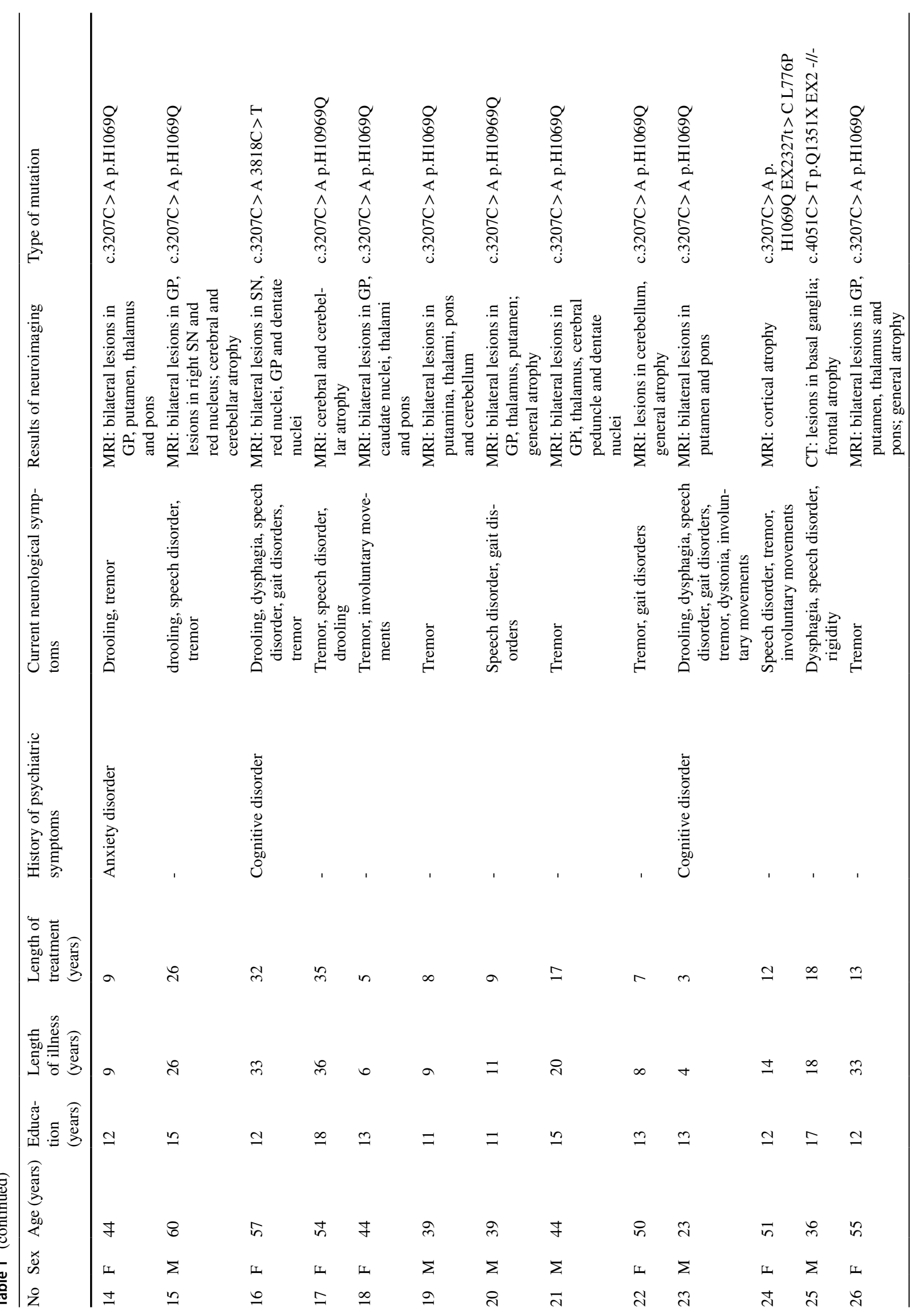




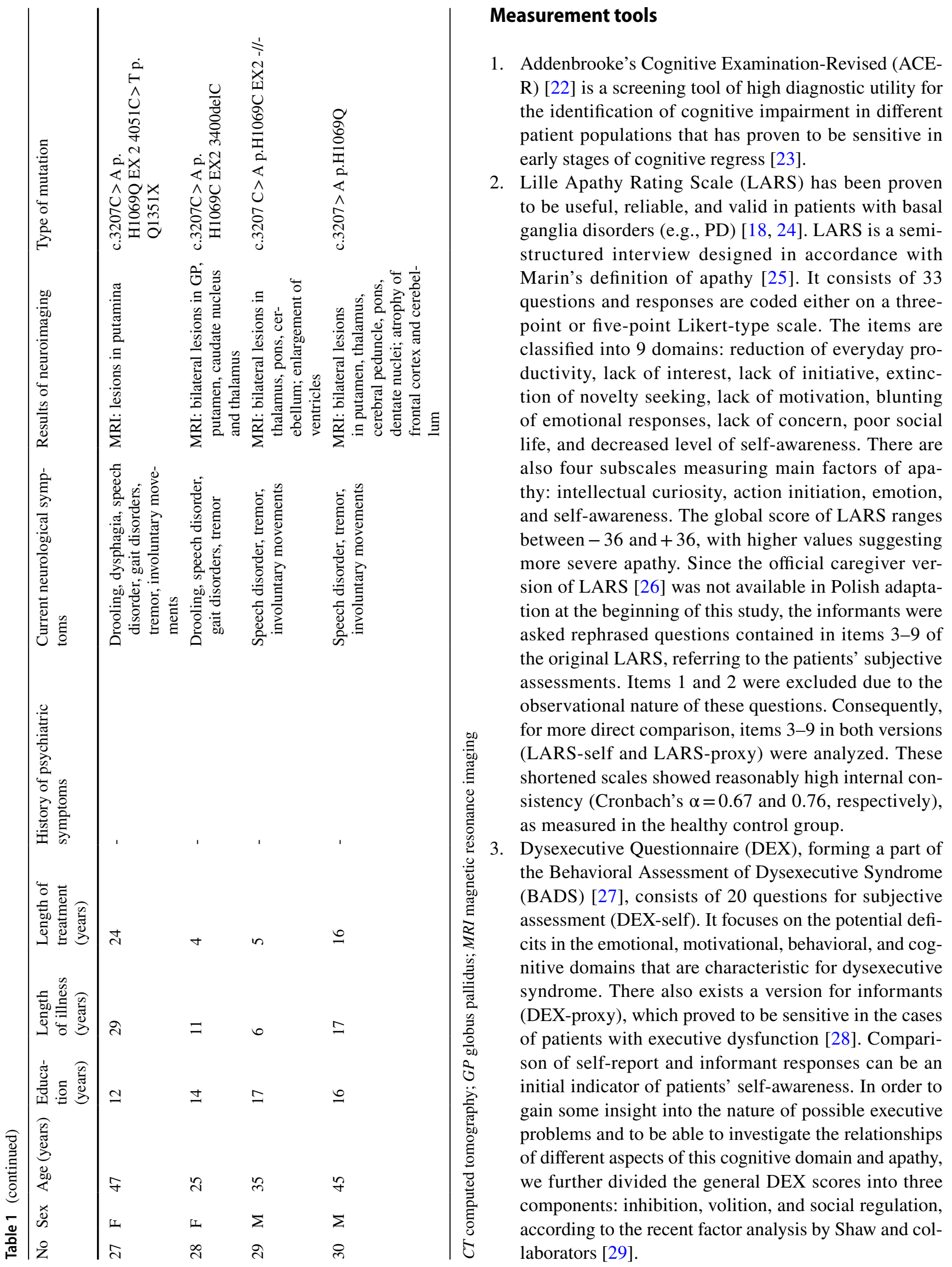


Table 2 Characteristics of WD patients and healthy controls

\begin{tabular}{llllll}
\hline Group & Male/female ratio & $\begin{array}{l}\text { Age (years) } \\
\text { Mean }(S D)\end{array}$ & $\begin{array}{l}\text { Education (years) } \\
\text { Mean }(S D)\end{array}$ & $\begin{array}{l}\text { Disease duration } \\
(\text { years) } \\
\text { Mean }(S D)\end{array}$ & $\begin{array}{l}\text { Treatment duration } \\
(\text { years) }\end{array}$ \\
\hline WD $(n=30)$ & $16 / 14$ & $44.9(10.7)$ & $13.5(2.3)$ & $17.7(10.9)$ & $15.3(10)$ \\
Control $(n=30)$ & $19 / 11$ & $43.1(13.2)$ & $14.4(2.8)$ & - & - \\
\hline
\end{tabular}

$S D$ standard deviation; $W D$ Wilson's disease

${ }^{a}$ Duration of disease: the time between onset of first symptoms and diagnosis

${ }^{\mathrm{b}}$ Treatment duration: the time between pharmacotherapy implementation and participation in the study

\section{Data analysis}

Data analyses were performed using R programming language. The differences between WD patients and healthy controls, in terms of both self-rated and proxy-rated LARS and DEX, were analyzed using two-way mixed ANOVA with group (WD or healthy controls) as a between factor and rater (self or proxy) as a within factor. Two healthy participants were excluded from the analysis of LARS results due to missing data (lack of LARS-proxy). Post hoc tests with Bonferroni correction were used to investigate specific differences if any effects were revealed in ANOVA. Any other differences between the two groups were tested using the independent t-test or Mann-Whitney $U$ test. To investigate any other linear relationships of variables, either Pearson $r$ or Spearman rho was calculated. In order to enable comparisons between the different analyses, $r$ coefficient was consequently used as an index of effect size. The level of significance was set at $p<0.05$.

\section{Results}

\section{Comparison of demographic characteristics}

Both groups were balanced in terms of age $(t[58]=0.602$, $p=0.55, r=0.08)$ and education $(U=367, p=0.215$, $r=-0.16)$. There were more male participants in the healthy control group, but the difference was not significant $\left(\operatorname{chi}^{2}[1]=0.27, p=0.6\right)$.

\section{Comparison of cognitive performance}

WD patients performed significantly poorer than healthy controls on ACE-R $(\mathrm{Med}=91.5, I Q R=8$ and $\mathrm{Med}=95.5$, $I Q R=4$, respectively; $U=191, p=0.001, r=-0.5)$. Since executive functioning might be of particular importance in this context, we also analyzed the total scores of the ACE-R's verbal fluency task as a regard of good measure of executive domain [30]. The WD group obtained significantly lower scores than healthy controls $(\mathrm{Med}=11, I Q R=2$ and $M e d=13, I Q R=1.5$, respectively; $U=166, p=0.001$, $r=-0.55)$ in this subtest.

\section{Comparison of LARS and DEX scores}

ANOVA revealed significant main effects of group on LARS scores $(F[1,56]=6.742, p=0.012, r=0.27)$. Post hoc tests clarified that this result could be attributed to the difference between proxy rates $(p=0.01)$ since the difference between self-ratings was not significant ( $p=0.31$; Fig. 1A).

Similarly, in the analysis of DEX, only group factor had significant impact on patients' scores $(F[1,58]=8.053$, $p=0.006, r=0.28)$. Again, the difference between proxy rates $(p=0.01)$ explained the abovementioned main effect while self-ratings were similar in both groups $(p=0.25$; Fig. 1B).

\section{Relationships between cognition and apathy}

In the WD group, LARS-self was related to neither ACE-R $(p=0.052)$ nor global DEX-self $(p=0.68)$. Similarly, there was no significant relationship of LARS-proxy in this group, either with ACE-R $(p=0.3)$ or with global DEX-proxy $(p=0.13)$. There was no significant relationship between LARS and DEX components in either version of these measures, except that between LARS-proxy and inhibitory component of DEX-proxy $(r=0.48, p=0.007)$.

To further investigate the possible relationship between cognitive impairment and apathy symptoms, we divided the clinical group into a subgroup of nine (30\%) patients fulfilling the ACE-R criteria for cognitive impairment (cut-off score 88) and those with higher scores. The Mann-Whitney $\mathrm{U}$ test did not reveal any significant differences between these two groups in any of the psychopathological measures except, not surprisingly, ACE-R verbal fluency $(U=169.5$, $p=0.001, r=0.64$ ).

In an attempt to roughly evaluate a frequency of apathy in neurological WD patients, we selected patients who 
Fig. 1 Comparison of LARS (A) and DEX (B) scores in a group of WD patients and healthy controls. Self: selfrating; Proxy: rating performed by a caregiver
A

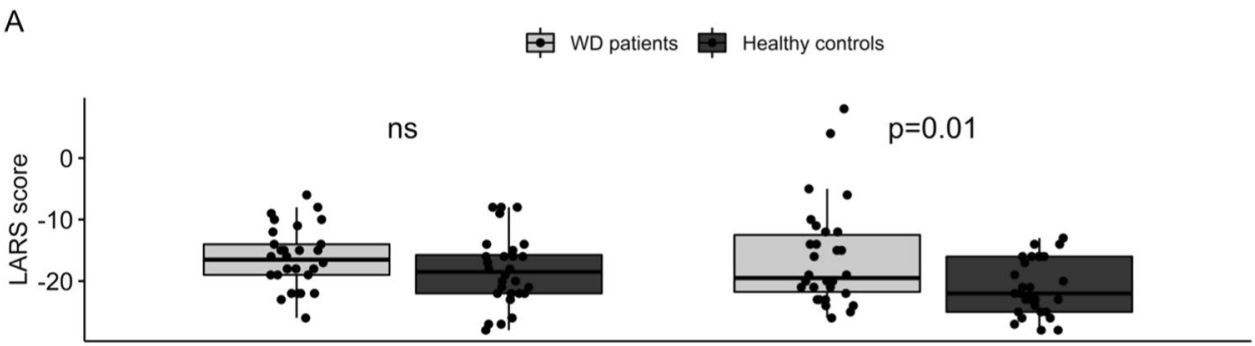

B

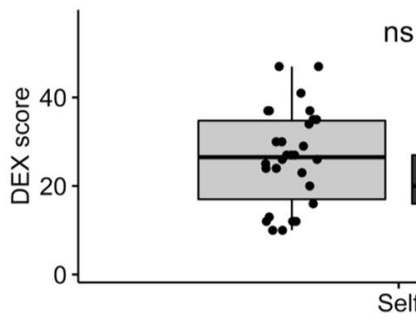

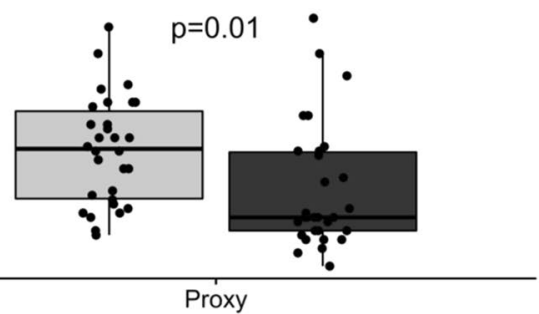

obtained scores higher than any of the participants from the healthy control group. In the case of LARS-self, there was only one patient ( $3 \%$; no. 2$)$ who met these criteria. However, when LARS-proxy was considered, the scores of eight patients (27\%; nos. 2, 4, 6, 12, 20, 23, 25, 30) were abnormally elevated. Interestingly, among these patients was only one female. Four (50\%) of these patients had previous history of psychopathology, including all three patients from the entire WD group who suffered from affective disorders in the past. Only three patients (37\%) had ACE-R scores below the cut-off point. The range of illness duration in this subgroup was 4-40 years.

\section{Discussion}

A clear tendency of patients with Wilson's disease to exhibit symptoms of apathy is the most important finding of this study. Significantly, these symptoms are reported by patients' caregivers and not by patients themselves. The same pattern applies to self-rated symptoms of executive dysfunction. It is very likely that due to poor insight, patients underestimated their psychopathological symptoms. It was estimated that roughly $30 \%$ of patients were likely to suffer from some degree of apathy since their scores in LARSproxy were higher than that of any of healthy controls.

There are numerous reasons for emergence of apathy in WD. The main anatomical correlates of apathy are pathological changes in the ventral striatum, dorsal anterior cingulate cortex, and other brain regions connected to the abovementioned [13]. Bhatia and Marsden [31] reviewed 240 cases of patients with lesions in the basal ganglia and concluded that $13 \%$ had relatively isolated significant adynamia, and of the latter, $70 \%$ were patients with caudate pathology. Severe apathetic-abulic disorders were also described in bilateral ischemic strokes involving the medial parts of the thalamus [32] and, as a consequence of damage to the medial parts of the frontal cortex [33], apathy was typically considered. All of these brain structures are susceptible to damage in the course of WD.

Changes in neurotransmission may be another important cause of apathy [34]. In patients with WD, dopamine deficiency - most likely associated with copper deposition in the basal ganglia-may play a crucial role in inducing apathy [35]. Although the reduction in dopaminergic projections is not as prominent as in PD, a recent study by McGuigan et al. [36] revealed that modulation of dopamine levels may reduce some symptoms of apathy.

As suggested by previous studies, the key difficulty in measuring apathy symptoms in WD is poor insight of patients into their mental functioning [37, 38]. Therefore, the use of the so-called self-report measurement tools does not seem to produce fully reliable results. Patients' limited self-awareness may lower the credibility of the interview and sometimes interfere with understanding and adherence to medical recommendations, which is essential for effective treatment. Self-description methods require the examined patient to have relatively intact metacognitive functions, i.e., insight into their own functioning, self-awareness, and ability to recognize their own deficits and preserved functions.

Self-awareness deficits may vary in intensity, from anosognosia to underestimating difficulties, and affect many or only selected domains of functioning. In the study by Seniów et al. [38], patients with the neurological form of WD rated their aggressiveness and interpersonal hypersensitivity in the Hopkins Symptoms Check List as lower than healthy controls, although increased irritability and conflictuality were usually emphasized (in the opinions 
of the patients' relatives). Furthermore, patients with the neurological form of WD seemed to respond less emotionally to their severe, chronic illness with motor disability compared to other chronic diseases, e.g., rheumatoid arthritis [39].

Therefore, more objective methods are needed to effectively detect and assess symptoms of apathy. We believe that evaluations performed by a family member/caregiver are more reliable (although not fully objective) than simple self-reports and can provide important information in this aspect of a patient's functioning.

Based on caregiver reports (LARS-proxy), it was found that apathy signs were independent of cognitive functioning. Individuals with clear cognitive impairment as measured by ACE-R (a slightly higher percentage of cognitive impairment than reported by Carta et al. [40] and Frota et al. [41] in the WD population) did not differ from the rest of patients in terms of the scores on descriptive clinical scales. This might be quite surprising since apathy is sometimes regarded as one of the aspects of executive dysfunction [42]. The relationship of WD and associated basal ganglia pathology with executive dysfunction is rather unquestionable in light of recent research [43]; however, research on the neurological form of WD shows that movement, cognitive, and emotional/motivational disorders are not strongly related. Although they often coexist, the degree of the deficit in each of the areas mentioned does not correlate with the severity of dysfunction in another [44]. In addition, psychopathological symptoms sometimes persist despite pharmacotherapy that is effective for the somatic (including motor) aspects of the disease.

It would appear that cognitive, emotional, and motivational changes in patients with WD could be partially related to subtle structural and functional abnormalities. These are often revealed by more sensitive and specific imaging techniques such as single-photon emission computed tomography [45, 46] or resting-state functional MRI [47]. Such techniques typically reveal pathological changes within a widespread network of both gray and white matter structures, which disrupt the functional connectivity crucial for cognitive, emotional, and motivational control [48].

Therefore, apathy seems to be another relatively independent area of psychopathology in WD. It is important to note, however, that until we have access to objective and sensitive measurement tools for these symptoms, all conclusions from studies using self-report and caregiverreport methods need to be treated with great caution.

Funding This study was supported by statutory activity of the Institute of Psychiatry and Neurology (501-15-021-20016). This work was supported by the Faculty of Psychology, University of Warsaw, from the funds awarded by the Ministry of Science and Higher Education in the form of a subsidy for the maintenance and development of research potential in 2020 (501-D125-01-1250000 zlec*. 5011000206).

Data availability Not applicable.

Code availability Not applicable.

\section{Declarations}

Ethical approval The study was approved by the Bioethics Committee of the Institute of Psychiatry and Neurology, Warsaw (No. 1/2008).

Consent to participate An informed consent was obtained from all participants.

Consent for publication Not applicable.

Conflict of interest The authors declare no competing interests.

Open Access This article is licensed under a Creative Commons Attribution 4.0 International License, which permits use, sharing, adaptation, distribution and reproduction in any medium or format, as long as you give appropriate credit to the original author(s) and the source, provide a link to the Creative Commons licence, and indicate if changes were made. The images or other third party material in this article are included in the article's Creative Commons licence, unless indicated otherwise in a credit line to the material. If material is not included in the article's Creative Commons licence and your intended use is not permitted by statutory regulation or exceeds the permitted use, you will need to obtain permission directly from the copyright holder. To view a copy of this licence, visit http://creativecommons.org/licenses/by/4.0/.

\section{References}

1. Członkowska A, Litwin T, Dusek P, Ferenci P, Lutsenko S, Medici V et al (2018) Wilson disease. Nat Rev Dis Primers 4(1):21. https://doi.org/10.1038/s41572-018-0018-3

2. Rosencrantz R, Schilsky M (2011) Wilson disease: pathogenesis and clinical considerations in diagnosis and treatment. Semin Liver Dis 31(3):245-259. https://doi.org/10.1055/s-0031-12860 56

3. Seniów J, Bak T, Gajda J, Poniatowska R, Czlonkowska A (2002) Cognitive functioning in neurologically symptomatic and asymptomatic forms of Wilson's disease. Mov Disord 17(5):1077-1083. https://doi.org/10.1002/mds.10195

4. Zimbrean P, Seniów J (2017) Cognitive and psychiatric symptoms in Wilson disease. Handb Clin Neurol 142:121-140. https://doi.org/10.1016/B978-0-444-63625-6.00011-2

5. Iwański S, Seniów J, Leśniak M, Litwin T, Członkowska A (2015) Diverse attention deficits in patients with neurologically symptomatic and asymptomatic Wilson's disease. Neuropsychology 29(1):25-30. https://doi.org/10.1037/neu0000103

6. Leśniak M, Członkowska A, Seniów J (2008) Abnormal antisaccades and smooth pursuit eye movements in patients with Wilson's disease. Mov Disord 23(14):2067-2073. https://doi. org/10.1002/mds.22276

7. Litwin T, Dusek P, Szafrański T, Dzieżyc K, Członkowska A, Rybakowski JK (2018) Psychiatric manifestations in Wilson's disease: possibilities and difficulties for treatment. Ther Adv Psychopharmacol 8(7):199-211. https://doi.org/10.1177/20451 25318759461 
8. Levy R, Czernecki V (2006) Apathy and the basal ganglia. J Neurol 253(Suppl 7):VII54-VII61. https://doi.org/10.1007/ s00415-006-7012-5

9. Stuss DT, Van Reekum R, Murphy KJ (2000) Differentiation of states and causes of apathy. The neuropsychology of emotion. Oxford University Press, New York, pp 340-363

10. Aarsland D, Marsh L, Schrag A (2009) Neuropsychiatric symptoms in Parkinson's disease. Mov Disord 24(15):2175-2186. https://doi.org/10.1002/mds.22589

11. Aarsland D, Litvan I, Larsen JP (2001) Neuropsychiatric symptoms of patients with progressive supranuclear palsy and Parkinson's disease. J Neuropsychiatry Clin Neurosci 13(1):42-49. https://doi.org/10.1176/jnp.13.1.42

12. Martinez-Horta S, Perez-Perez J, van Duijn E, Fernandez-Bobadilla R, Carceller M, Pagonabarraga J et al (2016) Neuropsychiatric symptoms are very common in premanifest and early stage Huntington's Disease. Park Relat Disord 25:58-64. https://doi. org/10.1016/j.parkreldis.2016.02.008

13. Le Heron C, Apps MAJ, Husain M (2018) The anatomy of apathy: a neurocognitive framework for amotivated behaviour. Neuropsychologia 118(Pt B):54-67. https://doi.org/10.1016/j.neuropsych ologia.2017.07.003

14 Van Reekum R, Stuss DT (2005) Ostrander L. Apathy: why care? J Neuropsychiatry Clin Neurosci 17(1):7-19. https://doi.org/10. 1176/jnp.17.1.7

15. Stanton BR, Carson A (2016) Apathy: a practical guide for neurologists. Pract Neurol 16(1):42-47. https://doi.org/10.1136/pract neurol-2015-001232

16. Levy R, Dubois B (2006) Apathy and the functional anatomy of the prefrontal cortex-basal ganglia circuits. Cereb Cortex 16(7):916-928. https://doi.org/10.1093/cercor/bhj043

17. Marin RS (1990) Differential diagnosis and classification of apathy. Am J Psychiatry 147(1):22-30. https://doi.org/10.1176/ajp. 147.1.22

18. Sockeel P, Dujardin K, Devos D, Denève C, Destée A, Defebvre L (2006) The Lille apathy rating scale (LARS), a new instrument for detecting and quantifying apathy: validation in Parkinson's disease. J Neurol Neurosurg Psychiatry 77(5):579-584. https:// doi.org/10.1136/jnnp.2005.075929

19. Radakovic R, McGrory S, Chandran S, Swingler R, Pal S, Stephenson L et al (2020) The brief Dimensional Apathy Scale: a short clinical assessment of apathy. Clin Neuropsychol 34(2):423435. https://doi.org/10.1080/13854046.2019.1621382

20. Brown RG, Pluck G (2000) Negative symptoms: the "pathology" of motivation and goal-directed behaviour. Trends Neurosci 23(9):412-417. https://doi.org/10.1016/s0166-2236(00)01626-x

21. Ferenci P, Czlonkowska A, Stremmel W, Houwen R, Rosenberg W, Schilsky M et al (2012) EASL Clinical Practice Guidelines: Wilson's disease. J Hepatol 56(3):671-685. https://doi.org/10. 1016/j.jhep.2011.11.007

22. Mioshi E, Dawson K, Mitchell J, Arnold R, Hodges JR (2006) The Addenbrooke's Cognitive Examination revised (ACE-R): a brief cognitive test battery for dementia screening. Int J Geriatr Psychiatry 21(11):1078-1085. https://doi.org/10.1002/gps.1610

23. Bruno D, Vignaga SS (2019) Addenbrooke's cognitive examination III in the diagnosis of dementia: a critical review. Neuropsychiatr Dis Treat 15:441-447. https://doi.org/10.2147/NDT.S151253

24. Weintraut R, Karádi K, Lucza T, Kovács M, Makkos A, Janszky J et al (2016) Lille Apathy Rating Scale and MDS-UPDRS for screening apathy in Parkinson's disease. J Parkinsons Dis 6(1):257-265. https://doi.org/10.3233/JPD-150726

25. Marin RS (1991) Apathy: a neuropsychiatric syndrome. J Neuropsychiatry Clin Neurosci 3(3):243-254. https://doi.org/10.1176/ jnp.3.3.243

26. Dujardin K, Sockeel P, Delliaux M, Destée A, Defebvre L (2008) The Lille Apathy Rating Scale: validation of a caregiver-based version. Mov Disord 23(6):845-849. https://doi.org/10.1002/mds. 21968

27. Wilson B, Emslie H, Evans J, Alderman N, Burgess P (1996) Behavioural assessment of the dysexecutive syndrome. Thames Valley Test, Bury St. Edmonds

28. Bennett PC, Ong B, Ponsford J (2005) Measuring executive dysfunction in an acute rehabilitation setting: using the dysexecutive questionnaire (DEX). J Int Neuropsychol Soc 11(4):376385. https://doi.org/10.1017/s1355617705050423

29. Shaw S, Oei TPS, Sawang S (2015) Psychometric validation of the dysexecutive questionnaire (DEX). Psychol Assess 27(1):138-147. https://doi.org/10.1037/a0038195

30. Amunts J, Camilleri JA, Eickhoff SB, Heim S, Weis S (2020) Executive functions predict verbal fluency scores in healthy participants. Sci Rep 10(1):11141. https://doi.org/10.1038/ s41598-020-65525-9

31. Bhatia KP, Marsden CD (1994) The behavioural and motor consequences of focal lesions of the basal ganglia in man. Brain 117(4):859-876. https://doi.org/10.1093/brain/117.4.859

32. Bogousslavsky J, Regli F, Delaloye B, Delaloye-Bischof A, Assal G, Uske A (1991) Loss of psychic self-activation with bithalamic infarction: neurobehavioural, CT, MRI and SPECT correlates. Acta Neurol Scand 83(5):309-316. https://doi.org/ 10.1111/j.1600-0404.1991.tb04708.x

33. Damasio AR (1985) Clinical neuropsychology. 2nd Ed. In: Heilman KH, Valenstein E, (Eds). Oxford University Press, New York, pp 409-460

34. Oh YS, Kim JH, Yoo SW et al (2021) Neuropsychiatric symptoms and striatal monoamine availability in early Parkinson's disease without dementia. Neurol Sci 42(2):711-718. https:// doi.org/10.1007/s10072-020-04859-8

35. Barthel H, Hermann W, Kluge R et al (2003) Concordant pre- and postsynaptic deficits of dopaminergic neurotransmission in neurologic Wilson disease. AJNR Am J Neuroradiol 24(2):234-238

36. McGuigan $\mathrm{S}$, Zhou SH, Brosnan MB, Thyagarajan D, Bellgrove MA, Chong TT (2019) Dopamine restores cognitive motivation in Parkinson's disease. Brain 142(3):719-732. https://doi.org/ 10.1093/brain/awy341

37. Portala K, Westermark K, Von Knorring L, Ekselius L (2000) Psychopathology in treated Wilson's disease determined by means of CPRS expert and self-ratings. Acta Psychiatr Scand 101(2):104-109. https://doi.org/10.1034/j.1600-0447.2000. 90085.x

38. Seniów J, Mroziak B, Członkowska A, Jędryka-Góral A (2003) Self-rated emotional functioning of patients with neurological or asymptomatic form of Wilson's disease. Clin Neuropsychol 17(3):367-373. https://doi.org/10.1076/clin.17.3.367.18085

39. Seniów J, Jędryka-Góral A, Członkowska A (1996) Neuropsychological impairment In Wison's Disease. Eur J Neurol 3(Suppl. 5):191-192

40. Carta M (2012) Quality of life and psychiatric symptoms in Wilson's disease: the relevance of bipolar disorders. Clin Pract Epidemiol Ment Heal 8(1):102-109. https://doi.org/10.2174/17450 17901208010102

41. Frota NAF, Barbosa ER, Porto CS, Lucato LT, Ono CR, Buchpiguel CA et al (2013) Cognitive impairment and magnetic resonance imaging correlations in Wilson's disease. Acta Neurol Scand 127(6):391-398. https://doi.org/10.1111/ane.12037

42. Zgaljardic DJ, Borod JC, Foldi NS, Rocco M, Mattis PJ, Gordon MF et al (2007) Relationship between self-reported apathy and executive dysfunction in nondemented patients with Parkinson disease. Cogn Behav Neurol 20(3):184-192. https://doi.org/10. 1097/WNN.0b013e318145a6f6

43. Wenisch E, De Tassigny A, Trocello JM, Beretti J, Girardot-Tinant N, Woimant F (2013) Cognitive profile in Wilson's disease: a case 
series of 31 patients. Rev Neurol (Paris) 169(12):944-949. https:// doi.org/10.1016/j.neurol.2013.06.002

44. Frota NAF, Caramelli P, Barbosa ER (2009) Cognitive impairment in Wilson's disease. Dement Neuropsychol 3(1):16-21. https:// doi.org/10.1590/S1980-57642009DN30100004

45. Giagheddu M, Tamburini G, Piga M et al (2001) Comparison of MRI, EEG, EPs and ECD-SPECT in Wilson's disease. Acta Neurol Scand 103(2):71-81. https://doi.org/10.1034/j.1600-0404. 2001.103002071.x

46. Piga M, Murru A, Satta L et al (2008) Brain MRI and SPECT in the diagnosis of early neurological involvement in Wilson's disease. Eur J Nucl Med Mol Imaging 35(4):716-724. https://doi. org/10.1007/s00259-007-0681-1
47. Tinaz S, Arora J, Nalamada K et al (2020) Structural and functional brain changes in hepatic and neurological Wilson disease. Brain Imaging Behav. https://doi.org/10.1007/s11682-020-004205.10.1007/s11682-020-00420-5

48. Hu S, Xu C, Dong T et al (2021) Structural and functional changes are related to cognitive status in Wilson's disease. Front Hum Neurosci 15:610947. https://doi.org/10.3389/fnhum.2021.610947

Publisher's note Springer Nature remains neutral with regard to jurisdictional claims in published maps and institutional affiliations. 